"The Complexity Era in Economics" by

Richard P.F. Holt, J. Barkley Rosser, Jr., and David Colander

January 2010

MIDDLEBURY COLLEGE ECONOMICS DISCUSSION PAPER NO. 10-01

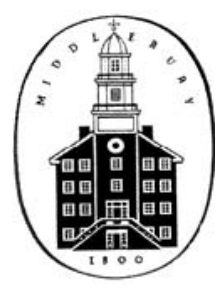

DEPARTMENT OF ECONOMICS

MIDDLEBURY COLLEGE

MIDDLEBURY, VERMONT 05753

http://www.middlebury.edu/ econ 


\title{
The Complexity Era in Economics
}

\author{
Richard P.F. Holt, Southern Oregon University, Ashland, Oregon, USA \\ J. Barkley Rosser, Jr., James Madison University, Harrisonburg, Virginia, USA \\ David Colander, Middlebury College, Middlebury, Vermont, USA
}

Correspondence address: Richard P.F. Holt, Southern Oregon University Ashland, Oregon, USA.

E-mail: rholt@sou.edu

\begin{abstract}
This article argues that the neoclassical era in economics has ended and is being replaced by a new era. What best characterizes the new era is its acceptance that the economy is complex, and thus that it might be called the complexity era. The complexity era has not arrived through a revolution. Instead, it has evolved out of the many strains of neoclassical work, along with work done by less orthodox mainstream and heterodox economists. It is only in its beginning stages. The article discusses the work that is forming the foundation of the complexity era, and how that work will likely change the way in which we understand economic phenomena and the economics profession.
\end{abstract}




\section{Introduction}

The neoclassical era in economics has ended and has been replaced by an unnamed era. ${ }^{1}$ We believe what best characterizes the new era is its acceptance that the economy is complex, and thus that it might be called the complexity era. The complexity era has not arrived through a revolution. Instead, it has evolved out of the many strains of neoclassical work, along with work done by less orthodox mainstream and heterodox economists. It is only in its beginning stages, but it is, in our view, the wave of the future. In this article, we provide our sense of the work that is forming the foundation of the complexity era, and how that work will likely change the way in which we understand economic phenomena and the economics profession.

\section{The Future of Economics}

Imagine for a moment that one were looking at the economics profession in England in 1890. One would say that Alfred Marshall with his blend of historical and analytical economics was the economics of the future; Walras's and Edgeworth's more mathematical approach would be considered minor players. Now fast forward to the 1930s_-Marshall is seen as a minor player, while Walras's and Edgeworth's mathematical approach has become the foundation for Samuelson’s cutting edge economics. Now imagine economics in 2050. Much of what is currently done in

\footnotetext{
${ }^{1}$ This argument was developed in our article “The Changing Face of Mainstream Economics," Review of Political Economy, Volume 16, Number 4, 485-499, October 2004b, and in our book The Changing Face of Economics: Conversations with Cutting Edge Economists (University of Michigan, 2004a). This article is based on material from our new book, J.B. Rosser, Jr., et al., European Economics at a Crossroads (Edward Elgar Press, 2010).
} 
economics will not be cited or even considered. Some parts of economics, which today are considered minor, will be seen as the forerunners of what economics will become.

The point of this comparison is to make clear that to judge the relevance of economic contributions one must be forward-looking. One must have a vision of what economics will be in the future, and judge research accordingly. Current journal publication and citation metrics don't do that; they have a status-quo bias because they are backward looking, and thus encourage researchers to continue research methods and approaches of the past, rather than developing approaches of the future. They are useful, obviously, because they show activity, but they are only part of the picture, and must be used in conjunction with specific knowledge of the researcher-what they are trying to do, what their vision of the future is, and how they see their work fitting in. Articles dotting i's and crossing t's, even ones that are cited relatively often in the short term, are far less important than articles that strike out in new directions. These are the ones that will change the direction of economics and be remembered in future history of economic thought texts.

Any system of assessment of literature has to be based on a judgment about the future direction of economics. If one does not, one is, by default, choosing the judgment that the current approach in the profession will continue. We have a definite view of the future of economics - there will be more acceptance that the economy is complex, and the profession, over time, will adopt certain kinds of technical mathematical, analytical and statistical tools to deal with that complexity. Models based on a priori assumptions will decrease, and be replaced by empirically driven models and assumptions. Behavioral economics will expand; experiments will become part of economist's tool kit, as will 
complex technical tools such as cluster analysis, ultra metrics, and dimensional analysis. This increasing complexity will be accompanied by a division of labor - theorists and statisticians will be become more and more specialized, but they will be complemented by economists who have a broad overview of where economics is going, and are trained in applying economics. Economics will stop trying to answer grand questions such as is the market preferred to command and control, or is the market efficient, and answer smaller questions such as what structure of market will achieve the ends that policy makers are trying to achieve.

Since the term complexity has been overused and over hyped, we want to point out that our vision is not of a grand complexity theory that pulls everything together. It is a vision that sees the economy as so complicated that simple analytical models of the aggregate economy—-models that can be specified in a set of analytically solvable equations - are not likely to be helpful in understanding many of the issues that economists want to address. Thus, the Walrasian neo-classical vision of a set of solvable equations capturing the full interrelationships of the economy that can be used for planning and analysis is not going to work. Instead, we have to go into the trenches, and base our analysis on experimental and empirical data. From there we build up, using whatever analytic tools we have available. This is different from the old vision where economists mostly did the opposite of starting at the top and then built down.

The complexity vision is not only what we believe connects the various research threads that will be the future of economics; it is also what we believe provides the best way to look at the economics profession itself-we see the economics profession as an evolving complex system that has competing forces operating at all times. It is a 
profession that can only be understood as a system in constant change and flux. Before we pursue these topics more, let us first try to define what complexity means.

\section{Definitions of Complexity}

Taking a complexity vision does not require choosing among the many specific definitions of complexity. ${ }^{2}$ But it is probably useful for us to note the most relevant views that are being bantered about in economics today. Three such views seem the most pertinent to us: a general view, a dynamic view, and a computational view. The general view is the most useful one for thinking of the evolution of economics as a discipline; the computational view is starting to become influential as a research methodology, and the dynamic view is relevant for both concerns. But a more general definition of a complex system is given to us by Herbert Simon:

Roughly by a complex system I mean one made up of a large number of parts that interact in a nonsimple way. In such systems, the whole is more than the sum of the parts, not in an ultimate metaphysical sense, but in the important pragmatic sense that, given the properties of the parts and the laws of their interaction, it is not a trivial matter to infer the properties of the whole. In the face of complexity, an in-principle reductionist may be at the same time a pragmatic holist (1962, p. 267).

Simon then goes on to emphasize how this definition leads to a focus on the hierarchical structure of systems, with Seth Lloyd identifying Simon's view as one of his 45 definitions, labeled “hierarchical.” Simon emphasizes that he is drawing on older literatures, particularly general systems theory (von Bertalanffy, 1962), which he sees as including the work of economist Kenneth Boulding with cybernetics (Wiener, 1948), and information theory (Shannon and Weaver, 1948). Of these, cybernetics can be seen as a

\footnotetext{
${ }^{2}$ Quite famously, the MIT physicist Seth Lloyd provided (at least) 45 definitions of this concept (Horgan, 1997, p. 303, footnote 11).
} 
foundational form of our second variety of complexity, dynamic complexity, while information theory can be seen as a foundational form of our third variety, computational complexity. ${ }^{3}$

The emphasis on the problem of the whole and the parts raises two issues that are central issues in economics and more recent approaches to complexity. One is clearly the problem of the relationship between micro and macro in economics, with this formulation calling to mind the old problem of Keynes's “fallacy of composition," although Walrasian approaches to macroeconomics have attempted to avoid this problem through the use of representative agent models. Some have proposed to deal with this problem through the invocation of an intermediate zone between the micro and the macro, the "meso,” which is seen as crucial to evolutionary dynamics of a complex economy (Ng, 1980; Dopfer, Foster, and Potts, 2004). ${ }^{4}$ The other is the phenomenon of the apparently spontaneous “emergence” of higher order structures out of lower order ones, an idea much emphasized by many at the Santa Fe Institute (Crutchfield, 1994), as well as by Austrian students of complexity (Lavoie, 1989), also sometimes labeled "anagenesis" (Boulding, 1978; Rosser, Folke, Günther, Isomäki, Perrings, and Puu, 1994). ${ }^{5}$

Simon's general definition also has the virtue of being close to the original meaning of the word "complex" as found in the Oxford English Dictionary (OED, 1971,

\footnotetext{
${ }^{3}$ Indeed, Simon saw the limits to human ability to compute as part of the foundation of bounded rationality. He saw part of this as involving the sort of logical paradoxes that concern the computational complexity people, and indeed his concern with these issues led him to become one of the "fathers of artificial intelligence" (Simon, 1969).

${ }^{4}$ Further development of this form of evolutionary approach as a foundation of a complexity view of economics can be found in Potts (2000), Metcalfe and Foster (2004), and Dopfer (2005). It is worth keeping in mind that the very term "neoclassical" was coined by Veblen, who posed the evolutionary approach as the most serious alternative to the neoclassical approach (Veblen, 1898), with Hodgson (2006) arguing that Darwinian evolution is the most fundamental of all complex systems.

${ }^{5}$ This approach can be seen as preceded by the British "Emergentist" School, which arguably first emerged in Mill (1843). See also Lloyd Morgan (1923).
} 
p. 492) where it is first defined as “a whole, comprehending in its compass a number of parts,” from the Latin “complectere,” meaning “to encompass, embrace, comprehend, comprise.” Among its partial synonyms is “complicated,” although, as Israel (2005) points out, this comes from a different Latin root, “complicare,” meaning "to fold together” or “interwoven” (OED, 1971, p. 493). Israel takes the strong position that this latter is a merely epistemological concept while the former is fundamentally ontological, complaining that such figures as von Neumann (1966) mistook them as identical, although this is arguably an overly strong position.

Finally, a virtue of this general definition is that it also encompasses one of the current cutting edge areas of economics, the behavioral and experimental approaches. Many who follow these approaches do not consider the complexity view to be all that relevant to what they do, Kenneth Binmore and Matthew Rabin for example. However, at the foundation of behavioral economics is the concept of bounded rationality, introduced originally by Herbert Simon. It is not just Simon, but many since who have seen complexity as implying that rationality must be bounded (Sargent, 1993; Arthur, Durlauf, and Lane, 1997), and thus is lying at the foundation of behavioral economics. ${ }^{6}$

The second definition is of dynamic complexity, which is arguably the most widely used form in economics, even though this is not per se on Lloyd's list of 45 definitions. Rosser (1999) has codified this as "broad tent complexity” and draws on Day (1994) for its definition. “A dynamical system is complex if it endogenously does not tend to asymptotically to a fixed point, a limit cycle, or an explosion” (Rosser, 1999, p. 170). Rosser then draws on the criticisms of “chaoplexity” by Horgan (1997) to argue

\footnotetext{
${ }^{6}$ For a discussion of the relation of Sargent to Simon, see Esther-Mirjam Sent, 1997.
} 
that this broad tent view contains four successive approaches based on nonlinear dynamics: ${ }^{7}$ cybernetics (Wiener, 1948), catastrophe theory (Thom, 1975), chaos theory (Dechert, 1996), and “small tent” (or heterogeneous agent-based) complexity. This latter is identified with approaches coming initially out of Brussels (Nicolis and Prigogine, 1977), Stuttgart (Haken, 1983), and the Santa Fe Institute, with Schelling (1971) being another predecessor. This approach emphasizes dispersed and interacting, heterogeneous agents (Arthur, Durlauf, and Lane, 1997; Hommes, 2006; Tesfatsion, 2006), and for many economists this is what they mean when they refer to "complexity models.”

Arthur, Durlauf, and Lane (1997, pp. 3-4) provide a summary of this approach through six characteristics: 1) dispersed interaction among heterogeneous agents, ${ }^{8}$ 2) no global controller in the economy, 3) cross-cutting hierarchies with tangled interactions, 4) continual adaptation and learning by evolving agents, 5) perpetual novelty, and 6) out-ofequilibrium dynamics with no presumption of optimality. This approach is seen as implying bounded rationality, not rational expectations, as noted above.

Finally we come to our third definition, that of computational complexity. While advocates of this approach emphasize its greater degree of precision, we shall also keep this to a more general level, as there are many different varieties of this concept, with

\footnotetext{
${ }^{7}$ It is generally argued that dynamically complex systems must be nonlinear, although not all nonlinear systems are complex. However, Goodwin (1947) showed that coupled linear systems with lags could exhibit what are described as complex dynamics, although the normalized equivalent of such a system is nonlinear, and Turing (1952) used such systems to develop his idea of morphogenesis.

${ }^{8}$ While it is generally argued that all this contradicts general equilibrium theory, Arrow has argued that "One of the things that microeconomics teaches you is that individuals are not alike. There is heterogeneity, and probably the most important heterogeneity here is heterogeneity of expectations. If we didn't have heterogeneity, there would be no trade. But developing an analytic model with heterogeneous agents is difficult" (Colander, Holt, and Rosser, 2004a, p. 301) This reminds us that while current macroeconomists like to describe their models as being "Walrasian," their assumptions of representative agents with rational expectations are far simpler than the assumptions in the Arrow-Debreu general equilibrium framework. Curiously, some of the greatest criticisms of the Arrow-Debreu general equilibrium framework have come from its own developers, as with the Sonnenschein-Mantel-Debreu Theorem (Debreu, 1974).
} 
arguably over half of the 45 definitions listed by Lloyd constituting one or another of its varieties. Many of these definitions are derived from the already-mentioned information theory of Shannon and Weaver (1948), e.g. Solomonoff (1964) and Kolmogorov (1965), which eventually boil down to descriptions of the minimum length of a computer program that will describe the information or system (Chaitin, 1987) or some variation of this (Rissanen, 1989). ${ }^{9}$ A harder line view is that a system is only truly computationally complex if it is not computable at all (Blum, Cucker, Shub, and Smale, 1998). ${ }^{10}$

Advocates of this approach (Albin with Foley, 1998; Velupillai, 2000, 2005, 2009; Markose, 2005) argue that its greater precision makes it a superior vehicle for scientific research in economics. It must be admitted that there is some truth to this. Nevertheless, the vast majority of research in economics that identifies itself with complexity tends to be more of the dynamic variety described above. Furthermore, this definition is certainly less useful when we consider the question of the economics profession itself as a complex evolving system. Here we consider that the first two definitions provide a more useful construct for analysis than this admittedly challenging and substantial view of complexity, which we expect has the potential for important future research in the area of economic complexity. Not only is the economics profession a set of hierarchies, but it also evolves through a set of local interactions among dispersed networks of influence.

\section{What Do We Mean by Cutting Edge Complexity Work?}

\footnotetext{
${ }^{9}$ Velupillai (2000, 2005, 2009) discusses the relationships between these different definitions.

${ }^{10}$ In such cases the program is of infinite length, that is, it does not halt. A fundamental source of this may involve problems associated with the incompleteness concept of Gödel (Lewis, 1985). An application to general equilibrium is due to Richter and Wong (1999).
} 
The definitions of complexity are important because they give us a way to integrate the many different strains of modern economics into a single unifying theme-the theme of complexity. The acceptance of the economics profession that they will have to deal with the fact that the economy is complex signals a new openness to ideas for other disciplines and complexity economics will be a transdisciplinary field. Some of the work currently being done which falls into this broad tent complexity approach include:

- Evolutionary game theory is redefining how institutions are integrated into the analysis.

- Ecological economics is redefining how nature and the economy are viewed as interrelating in a transdisciplinary formulation.

- Behavioral economics is redefining how rationality is treated.

- Econometric work dealing with the limitations of classical statistics is redefining how economists think of empirical proof.

- Complexity theory is offering a way of redefining how we conceive of general equilibrium and economic dynamics more broadly.

- Agent based computational economic (ACE) analysis is providing an alternative to analytic modeling.

- Experimental economics is changing the way economists think about empirical work, with this being the principal method by which behavioral economics is studied. 
These are changes that are ongoing, and which have, in varying degrees entered into the mainstream. As that has happened, there have been a broader set of changes in how mainstream economics sees itself. Modern economics is much more willing it seems today to accept that the formal part of economics has limited applicability, at least as currently developed. It is also far more willing to question economics' special status over the other fields of inquiry and to integrate the methods of other disciplines into their methods. $^{11}$

Each of these different strains has certain characteristics that are quite different from the characteristics of economics that one is presented with in economic textbooks. In most textbooks today one gets the impression that economics has not changed that much during the last 50 years. Essentially, one learns a paradigm that develops a simple analytic deductive model, sometimes called the Max U model. The microeconomics taught in these texts is some variation on the Max U model presented with little contextual flavor that characterized Marshall’s use of it. The Max U model presented in the standard text focuses almost entirely on efficiency and optimization, assuming agents are rational, selfish, and are operating in an environment that arrives at a unique equilibrium.

The MaxU model has been explored to death and, from a cutting edge view, is no longer of much interest. (That doesn't mean it doesn't still have considerable importance, and relevance, and that there are still many practical applications that warrant research; it is just to say that from a cutting edge standpoint, we've pulled about all we can from it).

\footnotetext{
${ }^{11}$ As we have argued elsewhere, (Colander, 1995) the approach we are describing is consistent with a Marshallian methodology, but inconsistent with a Walrasian methodology. See also Brian Loasby, 1989.
} 
That is why a major part of the new cutting-edge work is going beyond these assumptions; while it does not deny the usefulness and insight provided by that model, it does not see a model based only on these assumptions as sufficient, and is therefore pushing the envelope on each of those assumptions. Some examples of how cutting edge work is questioning these neoclassical assumptions would be the following:

- Cutting edge economics researchers are expanding the meaning of rationality to include a much broader range of agent actions that reflect actual actions; in the new approach, individuals are purposeful (incentives still matter) but are not necessarily formally rational. The new research considers the behavioral foundations of actions, using experiments to determine what people actually do, rather than simply basing their arguments on what people rationally should do. ${ }^{12}$ The work in game theory by such economists as Peyton Young (1998) is pushing rationality to its limits to demonstrate the importance of the expectations and information environment in people’s decisions. The cutting edge work that is being done here is going beyond the traditional definition of rationality, with extended versions of Herbert Simon's bounded rationality increasingly being accepted.

- Other cutting edge researchers are moving away from a narrow view of selfishness. While textbook economics generally presents a view of agents who care only about themselves, the new work is trying to come to grips with

\footnotetext{
${ }^{12}$ This work is beginning to integrate work in psychology such as John Payne et al (1993), which has used experimental methods to analyze choice and to see how people actually make decisions, rather than just assume "rationality." This work has found that context matters to a much greater extent than have been integrated with work in behavioral economics.
} 
the more realistic sense of individuals who, while they are self-interested, are also social beings, concerned about others and deriving happiness from interacting with others.

- Cutting edge researchers are moving away from the assumption of a unique equilibrium, and are dealing with much more complicated systems that have multiple equilibria, path dependency, and no clear-cut answer. A complex economy does not have a single equilibrium; it has many basins of attraction, and the question researchers ask is which basin is sustainable. In this work equilibrium is not a state of the economy; the economy is continually in flux.

Combined, these changes can be summarized as a movement in economics from a textbook economics of rationality, selfishness, and equilibrium to a new economics of purposeful behavior, enlightened self-interest, and sustainability. Cutting edge work is work that is helping to move that transformation along.

\section{Changes in Research Methods}

Another aspect of cutting edge work that is consistent with the complexity era involves changes in research methods that can serve as a catalyst for many changes in the profession. For example, advances in computing technology have led to new approaches such as agent based modeling that allows economists to analyze complicated systems, with much more complicated interactions. Instead of assuming optimal behavior, economists are using lab, field and natural experiments to determine what people actually do. As economists have started to use these new techniques they are taking notice of 
institutions, since the incentives embodied in those institutions are often central in understanding people's behavior.

This change is being accompanied by a change in the deductive nature of economic reasoning. The new work is based much more on empirical inductive reasoning, and far less on pure deductive reasoning. As this is happening, the math being used in economic analysis is becoming less the Bourbakian math of "theorem-proof," and more applied mathematics, which is designed to come up with answers about policy issues, and not just talk about general issues (Weintraub, 2002). Set theory and calculus, which come to definite results, are being replaced by game theory, which seldom comes to a definite conclusion independent of the precise structure of the game. For example the work on auctions combines insights from game theory with experimental results, which are then used in practice. Similarly, information economics is used in designing efficient algorithms for search engines.

\section{The Lack of Impact of Cutting Edge Work on Modern Macroeconomics}

Interestingly, these cutting edge changes in micro theory toward inductive analysis and a complexity approach have not occurred in macroeconomics. In fact, the evolution of macro economic thinking in the United States has gone the other way. By that, we mean that there has been a movement away from a rough and ready macro theory that characterized the macroeconomics of the 1960s toward a theoretically analytic macro theory based on abstract, representative agent models that rely heavily on the assumptions of equilibrium. This macro work goes under the name new Classical, Real 
Business cycle, and the dynamic stochastic general equilibrium (DSGE) theory, and has become the mainstream in the United States.

In part, this development in macro is understandable. As the new work has demonstrated, the macro theory that was prevalent in the 1960s claimed a much stronger theoretical foundation than was warranted, and many of the conclusions it came to were not supported by either empirical evidence or theory. However, while the new theoretical models have done a good job in eliminating the old theory, it is less clear as to what the new theoretical work has added to our understanding of the macro economy. At best, the results of the new macro models can be roughly calibrated with the empirical evidence, but often the calibration of these new models is no better than any other model, and the only claim they have to being preferred is aesthetic - they have micro foundations. However, it is a strange micro foundation-a micro foundation based on assumptions of no heterogeneous agent interaction, when, for many people intuitively, it is precisely the heterogeneous agent interaction that leads to central characteristics of the macro economy. This is essentially Keynes’ fallacy of composition insight.

In our view, the interesting cutting-edge work in macro is not in the theoretical developments organized around representative agent micro foundations work, but in the work that is going beyond that and viewing the macro economy as a complex system. In this work, one sees the macro economy as being endogenously organized. The issue is not why there are fluctuations in the macro economy, but instead, why is there so little 
instability where complex interactions intuitively could generate chaos. ${ }^{13}$ In this view, the thought that one could develop a micro foundation of macro without considering the feedback of the macro system on the individual is beyond belief. While it may still make sense to push analytic macro theory as far as one can, to see whether it will provide any insights, in the short term, such analytic extensions of analytically solvable pure theoretical models based on assumptions that are far from reality offer little hope for policy guidance. In the absence of a pure theoretical foundation, macro policy is best based more on statistical models that pull as much information as possible from the data. Empirical macro precedes theoretical macro.

\section{Conclusion}

When we first made the above arguments about complexity a decade ago, they were far more controversial than they are now. During that time, economics has changed and become more open to all the approaches we have suggested constitute complexity economics, so that now, it is becoming more and more, just economics. We are not saying that the movement to the complexity era is going to be smooth, or that the work is without problems. We recognize much of it has serious problems that will require a lot of work and weeding out. For example, some areas, such as experimental economics-have become fads, and an ever-increasing number of economists are including experimental work in their research. Such fads will require a weeding out, and a far more careful specification of what is an acceptable experiment and what isn't than currently exists.

\footnotetext{
${ }^{13}$ Of course, while true mathematical chaos is locally unstable, its fluctuations remain bounded, thus being consistent with the "corridor of stability" argument of Leijonhufvud $(1973,2009)$, along with the deep ecology idea of Holling (1973) of a possible tradeoff between resilience and stability.
} 
Other work, such as ACE modeling still has problems getting published because it doesn't fit well into a journal format, and it is very difficult to figure out precisely what we are learning from these models. Similar problems exist for the craftsman approach to econometrics discussed in Colander (2009), in which the econometrician interacts with the data and makes judgments while doing the analysis rather than working as a technician who is applying specific methods to data analysis. How does one judge the judgment? These issues will be debated over the next decade, and tentative answers will be arrived at. Once they are the true cutting edge economists will no longer be involved; they will have moved on to other problems. And this is the way that it should be in an ever changing, dynamic and evolving profession. 


\section{REFERENCES}

Albin, Peter S. with D. K. Foley (1998) Barriers and Bounds to Rationality: Essays in Economic Complexity in Interactive Systems (Princeton: Princeton University Press).

Arthur, W. B., Durlauf, S.N. \& Lane, D. A. (Eds) (1997) Introduction, in The Economy as an Evolving Complex System II (Redwood City: Addison-Wesley), pp. 1-14.

Bertalanffy, L. von (1962) General Systems Theory (New York: George Braziller).

Blum, L., Cucker, F., Shub, M. \& Smale, S. (1998) Complexity and Real Computation (New York: Springer-Verlag).

Boulding, K. E. (1978) Ecodynamics: A New Theory of Societal Evolution (Beverly Hills: Sage).

Chaitin, G. J. (1987) Algorithmic Information Theory (Cambridge: Cambridge University Press).

Chomsky, N. (1959) On Certain Formal Properties of Grammars, Information and Control (2), pp.137-167.

Colander, D. (1995) Marshallian General Equilibrium Analysis, Eastern Economic Journal, 21:3, pp: 281-293.

Colander, D. (Ed.) (2000) The Complexity Vision and the Teaching of Economics (Cheltenham: Edward Elgar).

Colander, D. (2009) “Economists, Incentives, and Empirical Work” EconomicEjournal. http://www.economics-ejournal.org/economics/journalarticles/2009-9.

Colander, D., Holt, R. P.F. \& Rosser, Jr., J.B. (2004a) The Changing Face of Economics: Conversations with Cutting Edge Economists (Ann Arbor: University of Michigan Press).

Colander, D., Holt, R. P.F. \& Rosser, Jr., J.B. (2004b) The Changing Face of Mainstream Economics, Review of Political Economy, 16, (4), pp. 485-499.

Crutchfield, J. (1994) The Calculi of Emergence: Computation, Dynamics and Induction, Physica D (75), pp.11-54.

Day, R. H. (1994) Complex Economic Dynamics, Volume I: An Introduction to Dynamical Systems and Market Mechanisms (Cambridge: MIT Press).

Day, R. H. (2007) The Complex Problem of Modeling Economic Complexity, in Massimo S. \& Colander, D. (Eds), Complexity Hints for Economic Policy (Milan: Springer), pp. 58-68. 
Debreu, G. (1974) Excess Demand Functions, Journal of Mathematical Economics (1), pp. 15-21.

Dechert, W. D. (Ed.) (1996) Chaos Theory in Economics: Methods, Models and Evidence (Aldershot: Edward Elgar).

Dopfer, K. (Ed.) (2005) The Evolutionary Foundations of Economics (Cambridge: Cambridge University Press).

Dopfer, K., Foster, J. \& Potts, J. (2004) Micro-Meso-Macro, Journal of Evolutionary Economics (14), pp. 263-279.

Goodwin, R. M. (1947) Dynamic Coupling with Especial Reference to Markets having Production Lags, Econometrica (15), pp.181-204.

Haken, H. (1983) Synergetics: Non-equilibrium Phase Transitions and Social Measurement, ${ }^{\text {rd }}$ ed, (Berlin: Springer-Verlag).

Hodgson, G.M. (2006) Economics in the Shadows of Darwin and Marx (Cheltenham: Edward Elgar).

Holling, C.S. (1973) Resilience and Stability of Ecological Systems, Annual Review of Ecology and Systematics (4), pp.1-24.

Hommes, C. H. (2006) Heterogeneous Agent Models in Economics and Finance, in Tesfatsion, L. \& Judd, K.L. (Eds.), Handbook of Computational Economics: AgentBased Computational Economics, Volume 2, (Amsterdam: North-Holland), pp. 11091188.

Horgan, J. (1997) The End of Science: Facing the Limits of Knowledge in the Twilight of the Scientific Age (paperback edition), (New York: Broadway Books).

Israel, G. (2005) The Science of Complexity: Epistemological Problems and Perspectives, Science in Context (11), pp.1-31.

Kolmogorov, A.N. (1965) Three Approaches to Quantitative Definition of Information, Problems of Information Transmission (1), pp.4-7.

Lavoie, D. (1989) Economic Chaos or Spontaneous Order? Implications for Political Economy of the New View of Science, Cato Journal (8), pp. 613-635.

Leijonhufvud, A. (1973) Effective Demand Failures, Swedish Journal of Economics (75), pp. 27-48.

Leijonhufvud, A. (2009) Out of the Corridor: Keynes and the Crisis, Cambridge Journal of Economics (33), pp.741-757. 
Lewis, A. A. (1985) On Effectively Computable Realizations of Choice Functions, Mathematical Social Sciences (10), pp. 43-80.

Lloyd Morgan, C. (1923) Emergent Evolution (London: Williams and Norgate).

Loasby, B. (1989) The Mind and Method of the Economist: A Critical Appraisal of Major Economists in the Twentieth Century (Cheltenham, England. Edward Elgar)

Markose, S. M. (2005) Computability and Evolutionary Complexity: Markets as Complex Adaptive Systems (CAS), Economic Journal (115), F159-F192.

Metcalfe, J. S. \& Foster, J. (Eds.) (2004) Evolution and Economic Complexity (Cheltenham: Edward Elgar).

Mill, J. S. (1843), Ratiocinative and Inductive Logic (London: Longmans Green).

Mirowski, Philip (2007) Markets Come to Bits: Evolution, Computation, and Markomata in Economic Science, Journal of Economic Behavior and Organization (63), pp. 209242.

Neumann, J. von, edited by Arthur W. B. (1966) Theory of Self-Reproducing Automata (Urbana: University of Illinois Press).

Ng, Y.K. (1980) Macroeconomics with Non-Perfect Competition, The Economic Journal (90), pp. 598-610.

Nicolis, G., I. Prigogine. (1977) Self-Organization in Nonequilibrium Systems: From Dissipative Structures to Order through Fluctuations (New York: WileyInterscience).

OED (1971) the Compact Edition of the Oxford English Dictionary, Volume A-O (Oxford: Oxford University Press).

Payne, J., J.Bettman, E. Johnson. (1993) The Adaptive Decision Maker (New York: Cambridge University Press).

Potts, J. (2000) The New Evolutionary Microeconomics: Complexity, Competence and Adaptive Behavior (Cheltenham: Edward Elgar).

Pryor, F. L. (1995) Economic Evolution and Structure: The Impact of Complexity on the U.S. Economic System (New York: Cambridge University Press).

Richter, M.K. \& Wong, K.C. (1999) Non-Computability of Competitive Equilibrium, Economic Theory (14), pp. 1-28.

Rissanen, J. (1989) Stochastic Complexity in Statistical Inquiry (Singapore: World Scientific). 
Rosser, J. B., Jr. (1999) On the Complexities of Complex Economic Dynamics, Journal of Economic Perspectives 13 (4), pp.169-192.

Rosser, J. B., Jr. (2004a) Complexity in Economics, Volumes I-III: The International Library of Critical Writings in Economics (174) (Cheltenham: Edward Elgar).

Rosser, J. B., Jr. (2004b) Epistemological Implications of Economic Complexity, Annals of the Japan Association for the Philosophy of Science, 13, pp.45-57.

Rosser, J. B., Jr. (Ed.) (2009a) Introduction, in Handbook of Complexity Research (Cheltenham: Edward Elgar), pp. 3-11.

Rosser, J. B. Rosser, Jr. (ED.) Computational and Dynamic Complexity in Economics, in (2009b) Handbook of Complexity Research. Cheltenham: Edward Elgar, pp. 22-35.

Rosser, J. B., Jr., Folke, C. Folke, G., Isomäki, H., Perrings, C. \& Puu, T. (1994), Discontinuous Change in Multilevel Hierarchical Systems, Systems Research, 11(3), pp. 77-93.

Rosser, J.B. Jr., Holt, R.P.F. and Colander, D. (2010), European Economics at a Crossroads, Cheltenham: Edward Elgar Press.

Sargent, T. J. (1993) Bounded Rationality in Macroeconomics (Oxford: Clarendon Press).

Schelling, T. C. (1971) Dynamic Models of Segregation, Journal of Mathematical Sociology, (1), pp. 143-186.

Sent, Esther-Mirjam. (1997) Sargent versus Simon: Bounded Rationality Unbound. Cambridge Journal of Economics, 21 (3), pp. 323-38.

Shannon, C. \&Weaver, W. (1948) The Mathematical Theory of Communication (Urbana: University of Illinois Press).

Simon, H. A. (1962) The Architecture of Complexity, Proceedings of the American Philosophical Society, (106), pp. 467-482.

Simon, H. A. (1969) The Sciences of the Artificial (Cambridge: MIT Press).

Solomonoff, R.J. (1964) A Formal Theory of Inductive Inference Parts I and II', Information and Control, 7, pp. 1-22; 224-254.

Tesfatsion, L. S. (2006) Agent-Based Computational Economics: A Constructive Approach to Economic Theory, in Tesfatsion, L. \& Judd, K.L. (Eds.), Handbook of Computational Economics: Agent-Based Computational Economics, Volume 2. Amsterdam: Elsevier, pp. 831-880.

Thom, R. (1975), (English translation), Structural Stability and Morphogenesis: An Outline of a Theory of Models (New York: Benjamin). 
Turing, A. M. (1952) The Chemical Basis of Morphogenesis, Philosophical Transactions of the Royal Society, B (237), pp. 37-72.

Veblen, T. (1898) Why is Economics not an Evolutionary Science? Quarterly Journal of Economics (12), pp. 373-397.

Velupillai, K. V. (2000) Computable Economics (Oxford: Oxford University Press).

Velupillai, K. V. (2005) A Primer on the Tools and Concepts of Computable Economics, in Velupillai K.V. (Ed), Computability, Complexity and Constructivity in Economic Analysis (Victoria: Blackwell), pp. 148-197.

Velupillai, K. V. (2009) A Computable Economist's Perspective on Computational Complexity, in Rosser, J.B. Jr. (Ed.). Handbook of Complexity Research. (Cheltenham: Edward Elgar), pp. 36-83.

Weintraub, E.R. (2002) How Economics Became a Mathematical Science (Durham: Duke University Press).

Wiener, N. (1948) Cybernetics, or Control and Communication in the Animal and the Machine (New York: Wiley \& Sons).

Young, H. P. (1998) Individual Strategy and Social Structure: An Evolutionary Theory of Institutions (Princeton: Princeton University Press). 